\title{
LETTERS
}

\section{Adverse health outcomes in transgender people}

In an article in CMAJ, Chan and colleagues reported on the case of a 44-year-old transgender woman with a deep vein thrombosis and history of immobility and high-dose estradiol. The authors state that transgender people often do not "have a regular family physician nor ongoing monitoring of [their] medications" and that they "may misuse estrogen therapy," leading to higher risks. ${ }^{1}$ The latter is not situated as a potential consequence of the former, and the authors overlook the inaccessibility of gender-affirming primary care.

Transgender people in Canada face "a multiplicity of challenges to their health and well-being" from the perspective of social determinants of health. ${ }^{2}$ In health care settings, studies have shown that many transgender people encounter inadequately trained physicians ${ }^{3,4}$ and face stigma and discrimination (e.g., refusal or termination of care, ridicule and the use of demeaning language ${ }^{5}$ ). These barriers lead to avoidance of health care and unmet health needs. ${ }^{4}$

To address this issue, programs such as Rainbow Health Ontario and Trans Care BC are expanding and improving access to sustainable gender-affirming care through the development of models of service and clinical resources, education of primary care providers and community engagement projects. Primary care providers are uniquely well-positioned to address both the general and gender-related health care needs of transgender people by using an approach that honours a patient's gender identity and expression.

In the introduction to an anthology of queer and trans health stories, Zena Sharman writes that "[w]e crowdsource our health in a community with a long history of caring for one another outside of and in spite of dominant systems and structures." ${ }^{6}$ The patient in this case also found support in her community; however, without acknowledging the barriers to accessing health care, Chan and colleagues perpetuate the false notion that transgender people, rather than transphobia and systemic inequities, are responsible for their adverse health outcomes.

\section{Marria Townsend MD}

Medical Director

\section{Haleema Jaffer MSI}

Medical student

\section{Lauren Goldman RN}

Nurse Educator, Trans Care BC,

Vancouver, BC

Cite as: CMAJ 2017 August 14;189:E1046. doi: $10.1503 / \mathrm{cmaj} .733239$

\section{References}

1. Chan W, Drummond A, Kelly M. Deep vein thrombosis in a transgender woman. CMAJ 2017;189:E502-4.

2. Bauer GR, Hammond R, Travers R, et al. "I don't think this is theoretical; this is our lives": how erasure impacts health care for transgender people. $J$ Assoc Nurses AIDS Care 2009;20:348-61.

3. Chan B, Skocylas R, Safer JD. Gaps in transgender medicine content identified among Canadian medical school curricula. Transgender Health 2016;1:142-50.

4. Giblon R, Bauer GR. Health care availability, quality, and unmet need: a comparison of transgender and cisgender residents of Ontario, Canada. BMC Health Serv Res 2017;17:283.

5. Bauer GR, Scheim Al. Transgender people in Ontario, Canada: statistics from the Trans PULSE Project to inform human rights policy. London (ON): Trans PULSE; 2015. Available: http://transpulseproject.ca/wp-content/uploads /2015/06/Trans-PULSE-Statistics-Relevant-for -Human-Rights-Policy-June-2015.pdf (accessed 2017 May 22).

6. Sharman Z, editor. The remedy: queer and trans voices on health and health care. Vancouver: Arsenal Pulp Press; 2016.

Competing interests: None declared. 